\title{
The Effects of Hydroalcoholic Extract of Satureja khuzestanica on Naloxone-Induced Morphine Withdrawal Symptoms in Wistar Rats
}

\author{
Bahareh Ebrahimi ${ }^{1,2}$, Saeed Esmaeili-Mahani ${ }^{2,3^{*}}$ \\ 'Shiraz Geriatric Research Center, Shiraz University of Medical Sciences, Shiraz, Iran. \\ ${ }^{2}$ Department of Biology, Faculty of Sciences, Shahid Bahonar University of Kerman, Kerman, Iran. \\ ${ }^{3}$ Laboratory of Molecular Neuroscience, Neuroscience Research Center, Institute of Neuropharmacology, Kerman \\ University of Medical Sciences, Kerman, Iran.
}

\section{*Correspondence to}

Saeed Esmaeili Mahani, Department

of Biology, Faculty of Sciences,

Shahid Bahonar University of Kerman,

Kerman, Iran, Postal Code: 76135-

133, Tel: $09133400062 .$,

Email: semahani@uk.ac.ir, semahani@ yahoo.com

Received February 162019

Accepted July 13, 2019

Published online March 31, 2020

\section{Abstract}

Introduction: The inflammatory system, oxidative stress, and cholinergic pathways are some important factors in long-term opioid dependence withdrawal. The adverse effects of some adjunctive medications on withdrawal symptoms treatment limit their clinical efficiency and finding compounds with inhibitory effects on opioid dependence can be helpful. The antioxidant, antinociceptive, and anti-inflammatory properties of Satureja khuzestanica extract (SKE) have been noted. Additionally, it_could reduce morphine analgesic tolerance. Given that no study has assessed the effect of SKE on morphine-induced withdrawal symptoms, we have tried to investigate it in this study.

Methods: Male Wistar rats were used in this study. The rats were treated with morphine for 7 days. The control group received saline, and intervention groups received SKE intragastrically by gavage $(100 \mathrm{mg} / \mathrm{kg}, 50 \mathrm{mg} / \mathrm{kg}$, and $25 \mathrm{mg} / \mathrm{kg}$ ) 15 minutes before morphine injections. Five hours after the last injection, naloxone was used and withdrawal symptoms were assessed for one hour. SPSS software version 16.0 was used for statistical analysis, and $P \leq 0.05$ was considered statistically significant.

Results: SKE diminished weight loss and jumping $(P \leq 0.001)$. It decreased grooming behaviors and cramps $(P \leq 0.01)$. SKE was found to decrease morphine withdrawal symptoms and 100 $\mathrm{mg} / \mathrm{kg}$ was the most effective dose. Additionally, different doses of SKE were able to eliminate ptosis, diarrhea, and teeth chattering in animals; however, different doses had different effects on withdrawal symptoms.

Conclusion: Naloxone significantly increased the frequency of jumping, cramps, weight loss, grooming, and induced ptosis, diarrhea, and teeth chattering. Treatment with SKE can significantly reduce morphine withdrawal symptoms. This can be done through its ability to decrease inflammation.

Keywords: Morphine, Satureja khuzestanica extract, Dependence, Withdrawal symptoms, Opioids

Please cite this article as follows: Ebrahimi B, EsmaeiliMahani S, The Effects of Hydroalcoholic Extract of Satureja khuzestanica on Naloxone-Induced Morphine Withdrawal Symptoms in Wistar Rats. Int J Basic Sci Med. 2020;5(1):16-21. doi:10.34172/ijbms.2020.04.

\section{Introduction}

Opioids are the most current analgesics for acute and chronic pain treatment. ${ }^{1,2}$ Since twenty years ago, fatal opiate overdoses have increased all over the world and those who have experienced non-fatal overdoses are expected to experience it again., 4

Continual usage of an opioid can induce long-lasting behavioral sensitization, which is shown to be associated with neuroplasticity that is generated by exposure to addictive drugs. Continued opioid use induces a variety of complications such as constipation, ${ }^{5}$ respiratory depression, ${ }^{6}$ and neuropathic pain. ${ }^{7}$ Patients with prolonged opioid exposure can have an increased risk of overdose, depression, and opioidinduced hyperalgesia. ${ }^{7,8}$ Cessation of opioid or any other drug administration after the continuous use of them is named

(c) 2020 The Author(s); Published by Zabol University of Medical Sciences. This is an open-access article distributed under the terms of the Creative Commons Attribution License (http://creativecommons.org/licenses/by/4.0), which permits unrestricted use, distribution, and reproduction in any medium, provided the original work is properly cited. 
withdrawal syndrome. ${ }^{9}$

Long-term agonist maintenance is a common clinical treatment option for patients' withdrawal. ${ }^{10,11}$ Under these situations, non-opioid adjunctive medications can reduce patients' withdrawal symptoms. ${ }^{12}$ However, the adverse effects of these medications restrict their use. ${ }^{13}$ In this regard, finding drugs and natural compounds with possible inhibitory effects on opioid dependence can be helpful. In the last years, medicinal herbs are more attractive due to fewer complications. ${ }^{14,15}$

In recent years, some experimental studies have indeed evaluated Iranian medical herbs using modern scientific methods for finding an effective treatment for different diseases. ${ }^{16-19}$ Satureja khuzestanica Jamzad (Lamiaceae) appears in small populations in the southern part of Iran, which is used as a muscle and neuropathic pain reliever in Iran traditional medicine. ${ }^{20}$ The anti-inflammatory, antimicrobial, and antinociceptive properties of the Satureja khuzestanica extract (SKE) have been shown in previous studies. ${ }^{21}$ This plant has antihyperalgesic effects on diabetic neuropathy and antinociceptive effects on morphine tolerance. ${ }^{22,23} \mathrm{SKE}$ exerts its effect on tolerated rats through an increase in the level of glial fibrillary acidic protein (GFAP) and also tumor necrosis factor-alpha $(\mathrm{TNF}) .{ }^{23}$ Based on the antioxidant, antinociceptive, and anti-inflammatory properties of SKE and its ability to induce morphine antinociceptive tolerance, ${ }^{21-23}$ this study was designed for investigating the effect of SKE on the morphine-dependent withdrawal syndrome in Wistar rat.

\section{Materials and Methods}

Animals

Male (200-250 g) Wistar rats were kept in isolation under specified pathogen-free conditions, controlled temperature $\left(22 \pm 0.5^{\circ} \mathrm{C}\right)$, and a $12 / 12 \mathrm{~h}$ light/dark cycle. Food and water were supplied ad libitum. Three days before the experiment, the animals were handled daily to minimize stress. The animals were randomly divided into 5 groups $(n=8)$. The experiments were done in accordance with ethical guidelines for investigations of experimental pain. ${ }^{24}$

\section{Preparation of Satureja khuzestanica Extract}

The SKE (ethanolic extract) was prepared in Razi Herbal Medicines Research Center, Lorestan, Iran. Leaves were dried and stored as a powder at the herbarium of the Razi Herbal Medicines Research Center. Air-dried leaves (200 g) were ground into a powder and then extracted twice, each time with $1 \mathrm{~L}$ ethyl alcohol (80\%). The extract was concentrated in a rotary evaporator under reduced pressure and then it was freeze-dried. Based on the results of gas chromatography-mass spectroscopy analysis, SKE contains carvacrol (78.3\%), 9-octadecenoic acid (13.5\%), hexadecanoic acid (6.7\%), bis (2-ethylhexyl) phthalate $(1.0 \%)$, and beta-bisabolene $(0.5 \%){ }^{22}$

\section{Study Design}

For this study, rats were divided into 5 different groups: control, morphine alone, morphine with normal saline (0.9\%), morphine with three different doses of SKE (100 $\mathrm{mg} / \mathrm{kg}, 50 \mathrm{mg} / \mathrm{kg}$, and $25 \mathrm{mg} / \mathrm{kg}$ ). Morphine was injected intraperitoneally (i.p.) 15 minutes after that the extract was given intragastrically (i.g.) by gavage. To assess morphine dependence, morphine was injected into the animals $(n=8)$ twice a day, for a week (an interval of 12 hours between injections). The used dosage and the work protocol are described in Figure 1. Five hours after the last morphine injection, $3 \mathrm{mg} / \mathrm{kg}$ naloxone was injected (i.p.). Withdrawal behaviors were then observed as described by Way et al. ${ }^{25}$ The animals were kept within a clear Plexiglas cylinder (a day before the experiment) and were observed for an hour. ${ }^{26,27}$

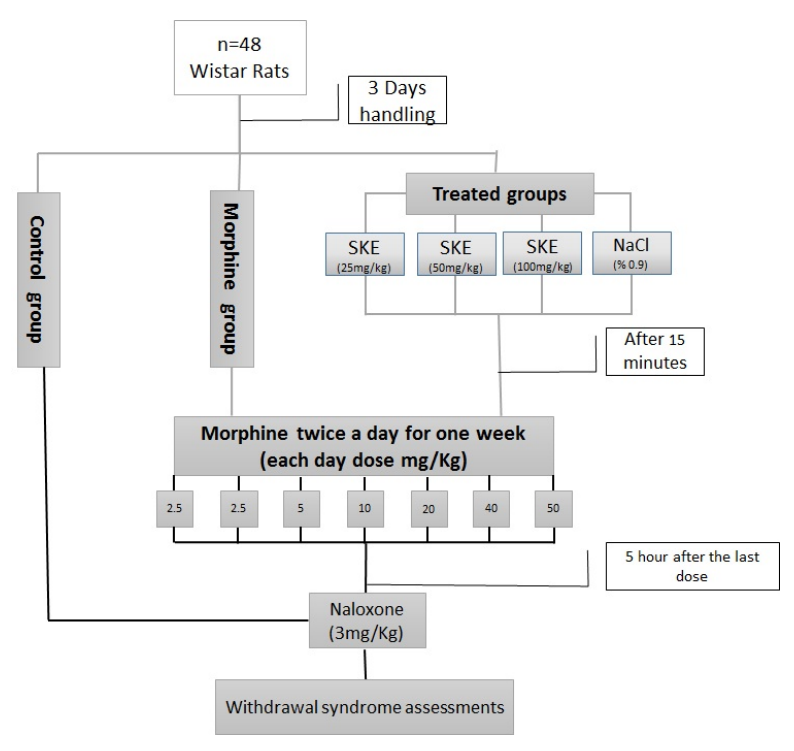

Figure 1. The Flowchart of the Study Design. 


\section{Withdrawal Symptoms Assessment}

A trained observer (blind to treatment) used a 7-item rating system which included autonomic, gastrointestinal, musculoskeletal, and mood symptoms. The scores varied across items for grooming, jumping and cramps, and their numbers per 1 hour were recorded. The rats were weighed before the naloxone injection, after 30 minutes, and after one hour of injection. Other factors, ptosis, diarrhea, and teeth chattering were scored either 0 (no indication of symptoms) or 1 (an indication of symptoms) and then all the responses of rats were summed.

\section{Statistical Analysis}

The data were presented as mean values \pm SD and analyzed using SPSS software version 16.0. Data comparisons were performed by analysis of variance (ANOVA). $P<0.05$ was considered statistically significant.

\section{Results}

\section{Results of Weight Loss Assessment}

To assess weight loss, rats were weighed directly before injection, 30 minutes after injection, and one hour after injection. In the morphine group, the weight significantly decreased after 1 hour compared with the initial weight. Weight loss with time was not significant in SKE treated rats and the control group (Figure 2).

\section{Results of Jumping Assessment}

The number of jumping increased after using naloxone in the morphine group in comparison with the control group. Using different doses of SKE could significantly decrease the mean number of jumping; however, there was no difference between the groups treated with different doses (Figure 3A).

\section{Results of Grooming Assessment}

Morphine and morphine $+100 \mathrm{mg} / \mathrm{kg}$ or $50 \mathrm{mg} / \mathrm{kg}$ SKE groups had a significantly higher level of grooming

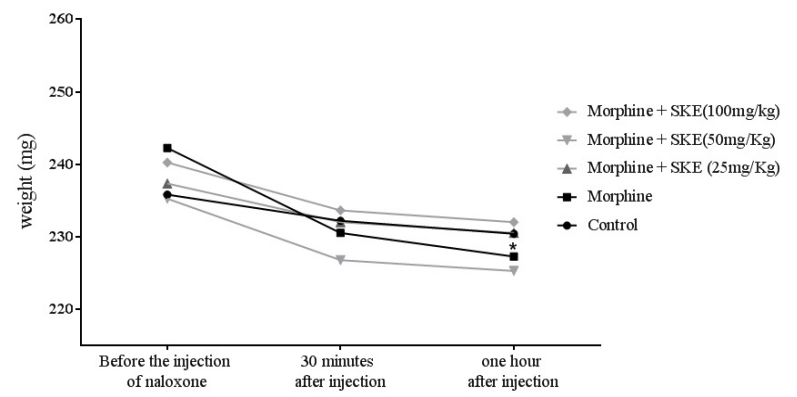

Figure 2. Effect of Different Doses of Satureja khuzestanica Extract on Weight Loss in Morphine-dependent Rats.

A significant difference was observed between before naloxone injection and one hour after injection. Results were expressed as means \pm SD. $P \leq 0.05$ was considered significant.
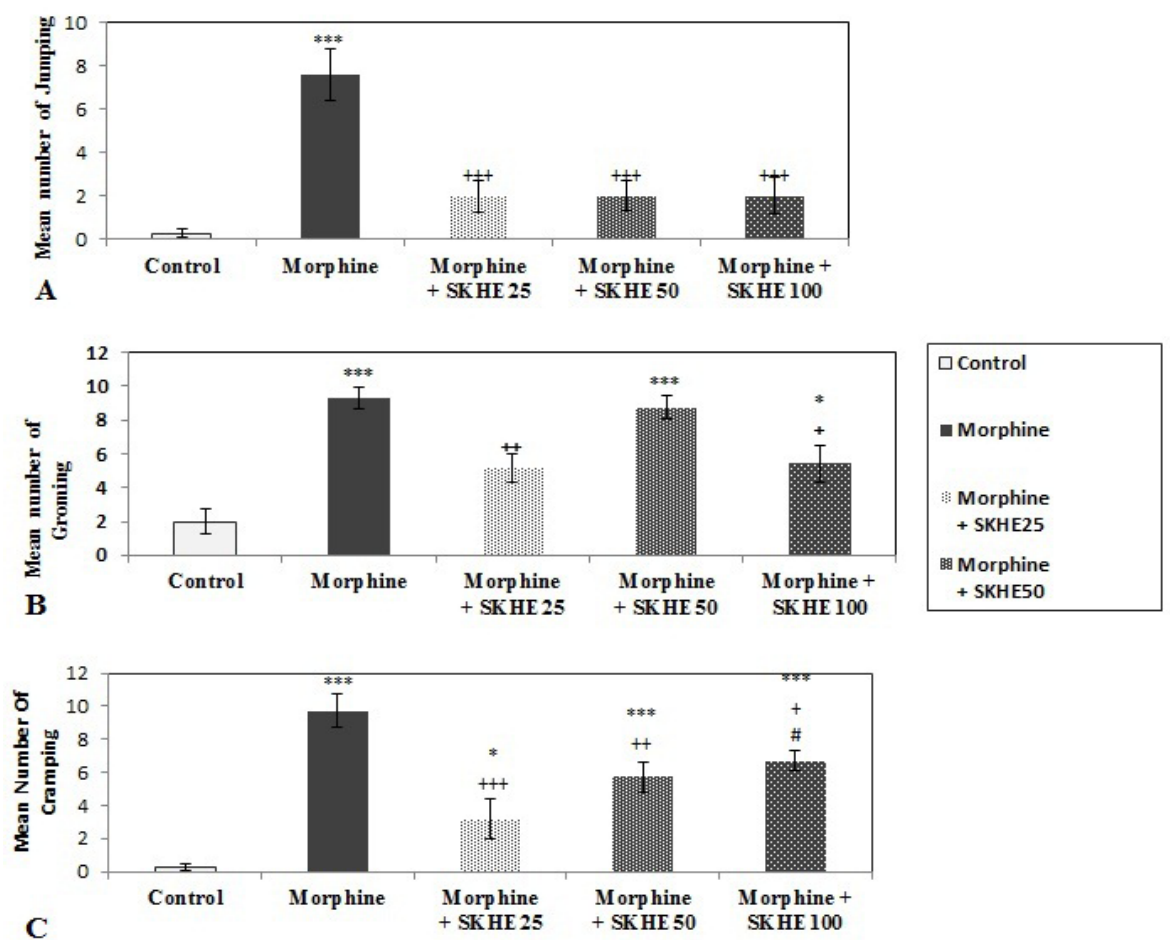

Figure 3. Effect of Different Doses of Satureja khuzestanica extract on Jumping (A), Grooming (B), and Cramps (C) in Morphine-dependent Rats. Results are expressed as means \pm SD. Comparison with control group: $* P \leq 0.05$, ${ }^{* *} P \leq 0.01$; comparisons with other group: $+P \leq 0.05),++P \leq 0.01,+++P \leq 0.001$. 
compared with the control group. Using $100 \mathrm{mg} / \mathrm{kg}$ and $25 \mathrm{mg} / \mathrm{kg}$ SKE could significantly decrease this side effect in comparison with the morphine group (Figure 3B).

\section{Results of Cramp Assessment}

The number of cramps after using naloxone in all treatment groups was higher in comparison with the control group. Using different doses of SKE significantly decreased the number of cramps, and the most effective dose of SKE was $50 \mathrm{mg} / \mathrm{kg}$ (Figure 3C).

\section{Ptosis, Diarrhea, and Teeth Chattering Assessments}

Ptosis, diarrhea, and teeth chattering were observed in the morphine group; however, using SKE decreased them in the last two quarters (after 30 minutes). The best effects belonged to the morphine $+100 \mathrm{mg} / \mathrm{kg} \mathrm{SKE}$ group. Regarding ptosis, the effects of other doses were not significant (Table 1).

\section{Discussion}

Naloxone is an opioid receptors antagonist that prevents opioids from acting and induces the addiction withdrawal symptoms in opioid-addicted patients. ${ }^{28}$ Physical symptoms like diarrhea, grooming, ptosis, cramp, jumping, weight loss, and teeth chattering are the main withdrawal syndrome symptoms in rats that can be assessed. ${ }^{25}$ Pharmaceutical drugs can stop morphine withdrawal; however, their adverse side effects can lead to the suggestion of using medicinal plants with natural effective substances which can cause fewer side effects and lower costs. ${ }^{12,14,15}$ SKE has shown the ability to reduce pain $^{21,22}$ and morphine tolerance. ${ }^{23}$

As this study showed, using SKE could decrease the symptom of morphine withdrawal and $100 \mathrm{mg} / \mathrm{kg}$ of SKE extract was the most effective dose. Using SKE could decrease weight loss, jumping, grooming, and cramps after the injection of naloxone. In a number of rats, different doses of the extract especially $100 \mathrm{mg} / \mathrm{kg}$ were able to eliminate ptosis, diarrhea, and teeth chattering.

Studies established that jumping during morphine withdrawal could be mediated by muscarinic or nicotinic cholinergic receptors. ${ }^{29,30}$ According to some previous studies, diarrhea occurs due to the effect of morphine on the cholinergic system. ${ }^{31}$ Previous studies have shown that an increased acetylcholine release during withdrawal can inhibit jumping. This release may be a secondary response to some primary withdrawal effector. ${ }^{32}$ The primary mechanism for the withdrawal is not known; however, a rapid increase in brain dopamine levels which occur after naloxone injection in morphine-dependent mice can be an example. ${ }^{33}$ Drugs affecting cholinergic and dopaminergic pathways in central nervous system (CNS) can affect the naloxone-induced jumping behavior. ${ }^{29,30,34}$ Some medicinal plants with flavonoid and phenolic compounds could reduce withdrawal syndrome by preventing the function of the cholinergic system through inhibiting cholinesterase. ${ }^{35}$ In a study, Borago officinalis flowers, which contain large amounts of flavonoids and phenolic compounds, were reported to inhibit the function of the cholinergic system and decrease withdrawal symptoms. ${ }^{14}$ A new monoterpene-flavonoid and twelve known flavonoids were isolated from an ethyl acetate extract of $S$. khuzestanica Jamzad, ${ }^{36}$ therefore, SKE can exert its effects through its flavonoids efficacy on the function of cholinergic system.

On the other hand, in the cholinergic anti-inflammatory pathway which receives signals from the efferent vagus nerve, there are interactions between these nerves, macrophages, and other immune cells through nicotinic acetylcholine receptors. ${ }^{37-39}$ In addition, brain cholinergic associations with the vagal-mediated cholinergic antiinflammatory pathways take a role in regulating systemic inflammation. ${ }^{39}$ This cholinergic modulatory effect can be used as a novel therapeutic modality for controlling excessive inflammation. ${ }^{37,40}$ According to these studies, using anti-inflammatory components can reduce withdrawal symptoms. It is proven that $S$. khuzestanica has an anti-inflammatory effect on inflammatory pain ${ }^{21}$ and can also reduce the morphine-induced elevation of TNFa level. ${ }^{23}$ Therefore, it seems that the reduction of morphineinduced cytokine-mediated neuroinflammation and the subsequent neuronal plasticity by SKE are the possible mechanisms for its effects on morphine dependence.

In this experimental project, the clinical symptoms of cramps and diarrhea, which were observed during naloxone-induced withdrawal, decreased after using different doses of SKE. Another study showed that the pharmacological modulation of glial activity with

Table 1. The Effect of Different Doses of Satureja khuzestanica Extract on Ptosis, Diarrhea, and Teeth Chattering in Morphine-Dependent Rats

\begin{tabular}{|c|c|c|c|c|c|c|c|c|c|c|c|c|}
\hline \multirow[b]{2}{*}{ Groups } & \multicolumn{3}{|c|}{ 0-15 minutes } & \multicolumn{3}{|c|}{$15-30$ minutes } & \multicolumn{3}{|c|}{ 30-45 minutes } & \multicolumn{3}{|c|}{ 45-60 minutes } \\
\hline & Ptosis & Diarrhea & $\begin{array}{c}\text { Teeth } \\
\text { Chattering }\end{array}$ & Ptosis & Diarrhea & $\begin{array}{c}\text { Teeth } \\
\text { Chattering }\end{array}$ & Ptosis & Diarrhea & $\begin{array}{c}\text { Teeth } \\
\text { Chattering }\end{array}$ & Ptosis & Diarrhea & $\begin{array}{c}\text { Teeth } \\
\text { Chattering }\end{array}$ \\
\hline Morphine & $8 / 8$ & $8 / 8$ & $8 / 8$ & $8 / 8$ & $8 / 8$ & $8 / 8$ & $8 / 8$ & $8 / 8$ & $8 / 8$ & $8 / 8$ & $8 / 8$ & $8 / 8$ \\
\hline Morphine $+\mathrm{NaCl}$ & $8 / 8$ & $8 / 8$ & $8 / 8$ & $8 / 8$ & $8 / 8$ & $8 / 8$ & $8 / 8$ & $8 / 8$ & $8 / 8$ & $8 / 8$ & $8 / 8$ & $8 / 8$ \\
\hline Morphine+ SKE (25 mg/kg) & $7 / 8$ & $6 / 8$ & $6 / 8$ & $8 / 8$ & $4 / 8 *$ & $4 / 8^{*}$ & $8 / 8$ & $1 / 8^{* *}$ & $1 / 8^{* *}$ & $8 / 8$ & $1 / 8^{* *}$ & $1 / 8^{* *}$ \\
\hline Morphine+ SKE (50 mg/kg) & $8 / 8$ & $6 / 8$ & $6 / 8$ & $7 / 8$ & $6 / 8$ & $6 / 8$ & $5 / 8$ & $2 / 8^{* *}$ & $2 / 8^{* *}$ & $6 / 8$ & $3 / 8^{*}$ & $3 / 8^{*}$ \\
\hline Morphine+ SKE (100 mg/kg) & $8 / 8$ & $5 / 8$ & $5 / 8$ & $6 / 8$ & $6 / 8$ & $6 / 8$ & $2 / 8^{* *}$ & $1 / 8^{* * *}$ & $1 / 8^{* *}$ & $2 / 8^{* *}$ & $3 / 8^{*}$ & $3 / 8^{*}$ \\
\hline
\end{tabular}


ibudilast decreased the opioid withdrawal symptoms in humans. ${ }^{13}$ This study showed that two ibudilast groups had lower ratings of withdrawal symptoms on SOWS items ("anxious", "perspiring", "restless", and "stomach cramps". ${ }^{13}$ Astrocyte cells express GFAP in CNS which is involved in some of the important processes such as chronic morphine-treatments. ${ }^{13,23}$ Our previous study showed that SKE prevented chronic morphine-induced GFAP activation. ${ }^{23}$ Moreover, withdrawal symptoms can be mediated by this function of SKE.

\section{Conclusion}

In conclusion, this study showed that the ethanolic extract of S. khuzestanica can significantly reduce morphine withdrawal symptoms. This can be done through its ability to decrease inflammation. Further pharmacological studies on traditional herbal drugs are needed to obtain evidence about the usefulness of medicinal plants in phytotherapy.

\section{Ethical Approval}

The experiments were approved by the Animal Experimentation Ethics Committee of Kerman Neuroscience Research Center (EC/KNRC/91).

\section{Conflict of Interest Disclosure}

None.

\section{Authors' Contribution}

SEM designed the study, BE performed the data collection and data analysis. All authors have contributed to the conception of the research, drafting the article, or revising it and approved the final version.

\section{Acknowledgements}

This manuscript is derived from the MSc thesis of Bahareh Ebrahimi. This project was supported by grants from Shahid Bahonar University, Kerman Neuroscience Research Center, Kerman University of Medical Sciences, Razi Herbal Medicines Research Center, and Lorestan University of Medical Sciences.

\section{References}

1. Manchikanti L, Fellows B, Ailinani H, Pampati V. Therapeutic use, abuse, and nonmedical use of opioids: a ten-year perspective. Pain Physician. 2010;13(5):401-435.

2. Compton WM, Volkow ND. Major increases in opioid analgesic abuse in the United States: concerns and strategies. Drug Alcohol Depend. 2006;81(2):103-107. doi:10.1016/j.drugalcdep.2005.05.009

3. Preti A, Miotto P, De Coppi M. Deaths by unintentional illicit drug overdose in Italy, 1984-2000. Drug Alcohol Depend. 2002;66(3):275-282. doi:10.1016/s03768716(01)00207-1

4. Rudd RA, Seth P, David F, Scholl L. Increases in drug and opioid-involved overdose deaths - United States,
2010-2015. MMWR Morb Mortal Wkly Rep. 2016;65(5051):1445-1452. doi:10.15585/mmwr.mm655051e1

5. Wald A. Constipation: advances in diagnosis and treatment. JAMA. 2016;315(2):185-191. doi:10.1001/jama.2015.16994

6. Jolley CJ, Bell J, Rafferty GF, Moxham J, Strang J. Understanding heroin overdose: a study of the acute respiratory depressant effects of injected pharmaceutical heroin. PLoS One. 2015;10(10):e0140995. doi:10.1371/ journal.pone.0140995

7. Stoicea N, Russell D, Weidner G, et al. Opioid-induced hyperalgesia in chronic pain patients and the mitigating effects of gabapentin. Front Pharmacol. 2015;6:104. doi:10.3389/fphar.2015.00104

8. Volkow ND, Koroshetz W. Lack of evidence for benefit from long-term use of opioid analgesics for patients with neuropathy. JAMA Neurol. 2017;74(7):761-762. doi:10.1001/jamaneurol.2017.0466

9. O'Brien CP. Drug addiction. In: Goodman \& Gilman's the Pharmacological Basis of Therapeutics. 12th ed. New York: McGraw-Hill; 2011:649-666.

10. Bart G. Maintenance medication for opiate addiction: the foundation of recovery. J Addict Dis. 2012;31(3):207-225. doi:10.1080/10550887.2012.694598

11. Kleber HD. Pharmacologic treatments for opioid dependence: detoxification and maintenance options. Dialogues Clin Neurosci. 2007;9(4):455-470.

12. Stotts AL, Dodrill CL, Kosten TR. Opioid dependence treatment: options in pharmacotherapy. Expert Opin Pharmacother. 2009;10(11):1727-1740. doi:10.1517/14656560903037168

13. Cooper ZD, Johnson KW, Pavlicova M, et al. The effects of ibudilast, a glial activation inhibitor, on opioid withdrawal symptoms in opioid-dependent volunteers. Addict Biol. 2016;21(4):895-903. doi:10.1111/adb.12261

14. Rabiei Z, Lorigooini Z, Rafieian-Kopaei M. Effects of hydroalcoholic extract of Borago officinalis on naloxoneprecipitated withdrawal syndrome in morphine-dependent mice. Bangladesh J Pharmacol. 2016;11(4):824-9. doi:10.3329/bjp.v11i4.26915

15. Hosseinzadeh H, Nourbakhsh M. Effect of Rosmarinus officinalis L. aerial parts extract on morphine withdrawal syndrome in mice. Phytother Res. 2003;17(8):938-941. doi:10.1002/ptr.1311

16. Alipanah H, Bigdeli MR, Esmaeili MA. Inhibitory Effect of Viola odorata extract on tumor growth and metastasis in 4 T1 breast cancer model. Iran J Pharm Res. 2018;17(1):276291.

17. Ebrahimie M, Bahmani M, Shirzad H, Rafieian-Kopaei M, Saki K. A review study on the effect of Iranian herbal medicines on opioid withdrawal syndrome. J Evid Based Complementary Altern Med. 2015;20(4):302-309. doi:10.1177/2156587215577896

18. Nahid K, Fariborz M, Ataolah G, Solokian S. The effect of an Iranian herbal drug on primary dysmenorrhea: a clinical controlled trial. J Midwifery Womens Health. 2009;54(5):401-404. doi:10.1016/j.jmwh.2008.12.006

19. Mikaili P, Shayegh J, Sarahroodi S, Sharifi M. Pharmacological properties of herbal oil extracts used in Iranian traditional medicine. Adv Environ Biol. 2012;6(1):153-158. 
20. Zargari A. Medicinal Plants. Tehran: Tehran University Publications; 1990.

21. Amanlou M, Dadkhah F, Salehnia A, Farsam H, Dehpour AR. An anti-inflammatory and anti-nociceptive effects of hydroalcoholic extract of Satureja khuzistanica Jamzad extract. J Pharm Pharm Sci. 2005;8(1):102-106.

22. Kaeidi A, Esmaeili-Mahani S, Abbasnejad M, et al. Satureja khuzestanica attenuates apoptosis in hyperglycemic PC12 cells and spinal cord of diabetic rats. J Nat Med. 2013;67(1):61-69. doi:10.1007/s11418-012-0646-y

23. Esmaeili-Mahani S, Ebrahimi B, Abbasnejad M, Rasoulian B, Sheibani V. Satureja khuzestanica prevents the development of morphine analgesic tolerance through suppression of spinal glial cell activation in rats. J Nat Med. 2015;69(2):165-170. doi:10.1007/s11418-013-0796-6

24. Zimmermann M. Ethical guidelines for investigations of experimental pain in conscious animals. Pain. 1983;16(2):109-110. doi:10.1016/0304-3959(83)90201-4

25. Way EL, Loh HH, Shen FH. Simultaneous quantitative assessment of morphine tolerance and physical dependence. J Pharmacol Exp Ther. 1969;167(1):1-8.

26. Darvishzadeh-Mahani F, Esmaeili-Mahani S, Komeili G, Sheibani V, Zare L. Ginger (Zingiber officinale Roscoe) prevents the development of morphine analgesic tolerance and physical dependence in rats. J Ethnopharmacol. 2012;141(3):901-907. doi:10.1016/j.jep.2012.03.030

27. Zare L, Esmaeili-Mahani S, Abbasnejad $M$, et al. Oleuropein, chief constituent of olive leaf extract, prevents the development of morphine antinociceptive tolerance through inhibition of morphine-induced L-type calcium channel overexpression. Phytother Res. 2012;26(11):17311737. doi:10.1002/ptr.4634

28. Rafieian-Kopaei M, Gray AM, Spencer PS, Sewell RD. Contrasting actions of acute or chronic paroxetine and fluvoxamine on morphine withdrawal-induced place conditioning. Eur J Pharmacol. 1995;275(2):185-189. doi:10.1016/0014-2999(94)00770-8

29. Jensen KP, DeVito EE, Yip S, Carroll KM, Sofuoglu M. The cholinergic system as a treatment target for opioid use disorder. CNS Drugs. 2018;32(11):981-996. doi:10.1007/ s40263-018-0572-y

30. Ruan H, Sun J, Liu X, Liu L, Cui R, Li X. Cholinergic M(4) receptors are involved in morphine-induced expression of behavioral sensitization by regulating dopamine function in the nucleus accumbens of rats. Behav Brain Res. 2019;360:128-133. doi:10.1016/j.bbr.2018.12.009

31. Williams JT, Christie MJ, Manzoni O. Cellular and synaptic adaptations mediating opioid dependence. Physiol Rev. 2001;81(1):299-343. doi:10.1152/physrev.2001.81.1.299

32. Eriator II. Naloxone: acute opioid withdrawal syndrome or side effects? Anesth Analg. 1998;87(5):1214. doi:10.1097/00000539-199811000-00056

33. Iwamoto ET, Ho IK, Way EL. Elevation of brain dopamine during naloxone-precipitated withdrawal in morphinedependent mice and rats. J Pharmacol Exp Ther. 1973;187(3):588-567.

34. Gramsch C, Bläsig J, Herz A. Changes in striatal dopamine metabolism during precipitated morphine withdrawal. Eur J Pharmacol. 1977;44(3):231-240. doi:10.1016/00142999(77)90070-х

35. Baradaran A, Rabiei Z, Rafieian M, Shirzad H. A review study on medicinal plants affecting amnesia through cholinergic system. J Herbmed Pharmacol. 2012;1(1):3-9.

36. Malmir M, Gohari AR, Saeidnia S, Silva O. A new bioactive monoterpene-flavonoid from Satureja khuzistanica. Fitoterapia. 2015;105:107-112. doi:10.1016/j. fitote.2015.06.012

37. Pavlov VA, Tracey KJ. The vagus nerve and the inflammatory reflex--linking immunity and metabolism. Nat Rev Endocrinol. 2012;8(12):743-754. doi:10.1038/ nrendo.2012.189

38. Rosas-Ballina M, Tracey KJ. Cholinergic control of inflammation. J Intern Med. 2009;265(6):663-679. doi:10.1111/j.1365-2796.2009.02098.x

39. Tracey KJ. Physiology and immunology of the cholinergic antiinflammatory pathway. J Clin Invest. 2007;117(2):289296. doi:10.1172/jci30555

40. Pavlov VA, Tracey KJ. The cholinergic anti-inflammatory pathway. Brain Behav Immun. 2005;19(6):493-499. doi:10.1016/j.bbi.2005.03.015 